\title{
Game-based learning with native language hint and their effects on student academic performance in a Saudi Arabia community college
}

\author{
Bassam Zafar • Ahmed Mueen • Mohammad Awedh • \\ Mohammed Balubaid
}

Received: 22 August 2014/Revised: 30 September 2014/ Accepted: 20 October 2014/

Published online: 1 November 2014

(C) Beijing Normal University 2014

\begin{abstract}
The main goal of this study is to address the association between computer games and students' academic performance. Computer games provide promising opportunities to motivate and involve students in learning. The exceptional growth in numbers of youth playing computer games in Saudi Arabia has stimulated this study to be conducted. In this study, we compared the effectiveness of two learning methods: game-based learning and nongame-based learning. We also observed the effectiveness of providing important terms' Arabic meaning during the learning process. Both learning methods are designed and applied on teaching a computer networking course in community college. A total of 44 community college students were involved in the study; they were randomly assigned to two groups of equal size $(N=22)$. One of which used game-based learning method and the other one used nongame-based learning method. Furthermore, both groups were observed with and without native language hint. A knowledge test was conducted as the pretest and posttest. Students' experiences and opinions on both methods were collected through feedback questionnaires. Data analyses showed that the game-based learning with native language hint demonstrated good performance as compared to nongame-based learning without native language hint. The results showed that students who use game-based method perform better and are more motivated than those who use the non-gaming method. The results suggest that computer game and native language hint can be used in education as a tool to
\end{abstract}

B. Zafar · A. Mueen $(\varangle) \cdot$ M. Awedh $\cdot$ M. Balubaid

King Abdulaziz University, Jeddah, Saudi Arabia

e-mail: mueen@kau.edu.sa

B. Zafar

e-mail: bzafar@kau.edu.sa

M. Awedh

e-mail: mhawedh@kau.edu.sa

M. Balubaid

e-mail: mbalubaid@kau.edu.sa 
increase student's academic performance and motivation in non-English speaking countries.

Keywords Computer games - Improving classroom teaching $\cdot$ Interactive learning $\cdot$ Community college

\section{Introduction}

The important challenging issue is how to motivate student toward learning and improve the efficiency of teaching. In recent years, game-based learning has gained attention in academia, as it integrates education with entertainment and enhances student involvement (Prensky 2008; Cagiltay 2007; Papastergiou 2009a, b; Tüzün et al. 2009). The growth of game-based learning has largely impacted learning procedures owing to the rapid advancement of computer and multimedia technology (Shin et al. 2012; Hwang and $\mathrm{Wu}$ 2012). The emergence of educational games has further facilitated the wide adoption of game-based learning as a form of learnercentered learning that constitutes powerful learning environments (Ebner and Holzinger 2007). The potential of game-based learning has shown that they can aggravate active user participation through exploration, competition, co-operation, and experimentation (Klopfer et al. 2009). Visualization and creativity in games also support learning. Importantly, computer games have become very popular among the current generation. Studies show that computer games are the most common computer activity in home (Papastergiou and Solomonidou 2005; McFarlane et al. 2002). This mostly due to the fact that playing is a natural way to learn; it provides the opportunities for kids to unconsciously incorporate ideas (Petty 1997; Pivec 2007; Prensky 2007). Therefore, educational computer games are beneficial to most of the children since computer games provide more creative environment as compared to conventional learning environment. However, many parents and teachers feel computer games cause social illness among the children and they become addicted to games (Gentile and Anderson 2003; Giumetti and Markey 2007). As a result of their gaming obsession, student spends huge amount of time and effort on computer games (Hsu et al. 2009; Oggins and Sammis 2012; Starcevic et al. 2011). In addition, due to game addiction and playing games for increasingly longer periods of time student isolate themselves from other students as well as creating less sociable attitudes (Harris 2001). Despite all the negative concerns, studies show there is an increasing trend among teachers to exploring the use of games in their classrooms (Williamson 2009; Project Tomorrow, 2008). Along similar lines, it is reported that computer games had successfully made student to be attentive in classroom (Inal and Cagiltay 2007; Roussou 2004) and helping students to learn strategic thinking skills, and relating the game to in-class scenarios (Gonzalez-Gonzalez and Blanco-Izquierdo 2012). Definitely computer games still require lots of research to observe its impact on education according to different environment, scenarios, levels, and tools. At present, there has been growing interest in application of game-based learning in higher level Education 
institutions. There are few creative examples in which computer game has been used to improve teaching and learning in higher education (Ebner and Holzinger 2007; Virvou and Katsionis 2008). Lawrence (2004) used games to teach programming concepts in university of Iowa. In China, study conducted over undergraduate students with computer science majors enrolled in the software engineering course in one of the large university in China showed that student learned more from game-based learning than from purely face-to-face classroom instruction (Zhi and Zhang 2008). Player enjoyment is the most essential goal in gaming. Research has found that there is a correlation between enjoyment and use of technology (Venkatesh 2000). Furthermore, it is observed that learning science in a language other than the learner's native language will for the most part not allow learners to be creative enough, and nor will they be able to enjoy learning (Saleh Alshair 2014). The researcher (Amedeker 1998) found out that learning science could be eased when the students with low proficiency in English were given the option to employ their native language as a tool for learning science. Therefore, when students use computer games plus native language as a tool for them to learn subjects, their engagement in computer games appeared to be higher.

Most of the studies related to game-based learning were conducted in developed countries. There is high need for local study in Saudi Arabia due to the fact that there is robust increase in internet users and online gaming. The study in (Gulf News 2014) shows that due to the vigorous increase in internet users the Arab online gaming market is growing at an exponential rate. There are around 500,000 gamers in the Arab world on a monthly basis. Saudi Arabia and Egypt are the biggest online gamers. It is growing at around $50 \%$ year on year. Therefore, the purpose to conduct this study to addresses the question of whether computer games do help students learn effectively and motivate them for learning. It was designed on the basis of community college computer network program curriculum. Furthermore, we also observed student performance if native language hint is provided to the students during their learning process. This is due to the fact that although the medium of instruction is English in the college but all students use their mother tongue (Arabic) for their daily conversation. Therefore, majority of students do not have English proficiency up to the mark. Indeed, sometime it is hard for students to understand some concepts.

\section{Research hypotheses}

The aim of our study is to investigate the involvement of higher education students in computer games and the effect of computer games on their academic performance and furthermore, to investigate the effect of native language hint on student academic performance. The researcher in (Prensky 2001) believed that digital games comprise elements that can be combined within an instructional context that enhance the learning process. Education games can be integrated within the classroom as instructional activities. These educational games force learner to make decision, face challenges, and learn through trial and error (Mikalef et al. 2012). Furthermore, playing games give concept of relaxation, leisure, and 
excitement, which remove stress and release tension. Overall, educational games have great prospective for helping students to increase their learning performance (Huang et al. 2010). However, in traditional teaching instructors use their knowledge, humor, and movement to make student attentive and active (Nordkvelle et al. 2009). Additionally, in non-English speaking countries some time instructors use native language to explain the concepts. We collected data from higher education students to get their opinions about various aspects of the computer games and how native language hint helps student through a feedback questionnaire. The hypotheses of the study were formulated as follows:

H1 Students' gaining knowledge through game-based learning performs better than student acquiring knowledge through nongame-based learning.

H2 The learner sense of enjoyment with the game-based learning is significantly more than nongame-based learning.

H3 Student having native language hint build better subject vocabulary than student acquiring knowledge without any local language hint.

\section{Method}

Participants

The research was conducted at community college in Jeddah, Saudi Arabia. The samples were taken from 44 students; they were attending introduction to network subject of computer network curriculum. Students were enrolled in computer network program of associate degree. They were in their third semester. In total, two classes participated. Two groups were formed by randomly selecting students. The first group was the game-based learning group and the other was nongame-based learning group. The two groups consist of equal number of students. There is no female student in the college. Therefore, all the samples were taken from male students. Student participants were from the age 19 to 21 years. Participant characteristics are shown in Table 1.

\section{Materials}

Game was created compliant to the community college computer network program curriculum and targeting at introducing students to basic computer network concepts. The objectives of the game are that students learn about the following: (i) Types of computer network, (ii) Scope of computer networks, (iii) Computer network topologies, (iv) Computer network technologies, (v) Types of protocols, (vi) Protocols and data transmissions, (vii) Open systems interconnection reference model, (viii) Transmission control protocol/internet protocol (TCP/IP), (ix) Examining IP addressing, (x) Optimizing IP address allocation, (xi) Examining web services.

The cognitive theory of multimedia learning (CTML) (Mayer 2001) explains how multimedia instructional practices help people to learn efficiently. The CTML 
Table 1 Participant characteristics

\begin{tabular}{lll}
\hline & Game-based & Nongame based \\
\hline Respondents & 22 & 22 \\
Mean age & 19.6 & 20.1 \\
\hline
\end{tabular}

theory is based on the idea that people learn more profoundly from the combination of words and pictures than words alone. However, just adding words to pictures is not an effective way to accomplish multimedia learning. It is how to use instructional media in the light of how human mind works. Therefore, this theory may give us an explanation for the use of educational games as a mean to improve student learning. The researchers' believes (Papastergiou 2009a, b) that games can enhance student performance by constructing well-designed multimedia instructional messages that support cognitive development by taking into account CTML theory. Overall, educational games have great prospective for assisting students to improve their learning (Papastergiou 2009a, b). In the design of the game, the following points were taken into account: (i) the game should be easy to learn and easy to play, (ii) Arabic translation should be clear and simple, (iii) graphics should be simple and light; heavy three-dimensional graphics were avoided, (iv) the flow of the game should be kept relatively simple to avoid any confusion. The following implementation limitations were also taken into account: (i) the game should be runnable (with exe file) without the need of any software, (ii) the game should be in Windows platform, as all college computers using this platform, (iii) student should be able to finish the game within $1 \mathrm{~h}$ and $50 \mathrm{~min}$, as this is the duration allocated for each class in the college, (iv) the development and editing of the game should be simple given that it would be handled by one person (the researcher), to deal any type of situation easily. The game consists of seven rooms in the form of mazes according to seven chapters of the course. In each room or chapter, students required to solve a number of problems which were offered to him during game playing. These problems include true/false, multiple-choice and short answers questions (Fig. 1). Game was also linked with multimedia learning material, where concepts are explained with the help of image, text, graphics, and animations. To complete the level or one chapter successfully, student has to open all the doors available in the game. At the start of the game, a student is placed in the top left corner of the maze; he has to move down by opening the doors and escape from the spider. To kill the spider student has a weapon, which is an arrow that can be activated by space bar. Student needs to correctly answer all the questions presented to him and get the score in order to successfully finish the level. Furthermore, if student answers the question wrongly, a link will take student to a learning material, where, explanation of that particular topic is given. The questions asked in each chapter are 20.

We applied the approach of 'read, think, and try' (Natvig and Line 2004) instead of trial and failure method. To make game more lively, background music and different sound effects were added on specific action. At the start of the game, student possesses three lives and zero score. Student gets feedback whenever he answers the question. He loses one live in case of wrong answer and an explanation or a link is provided to the student to find the correct answer. Remaining lives and 


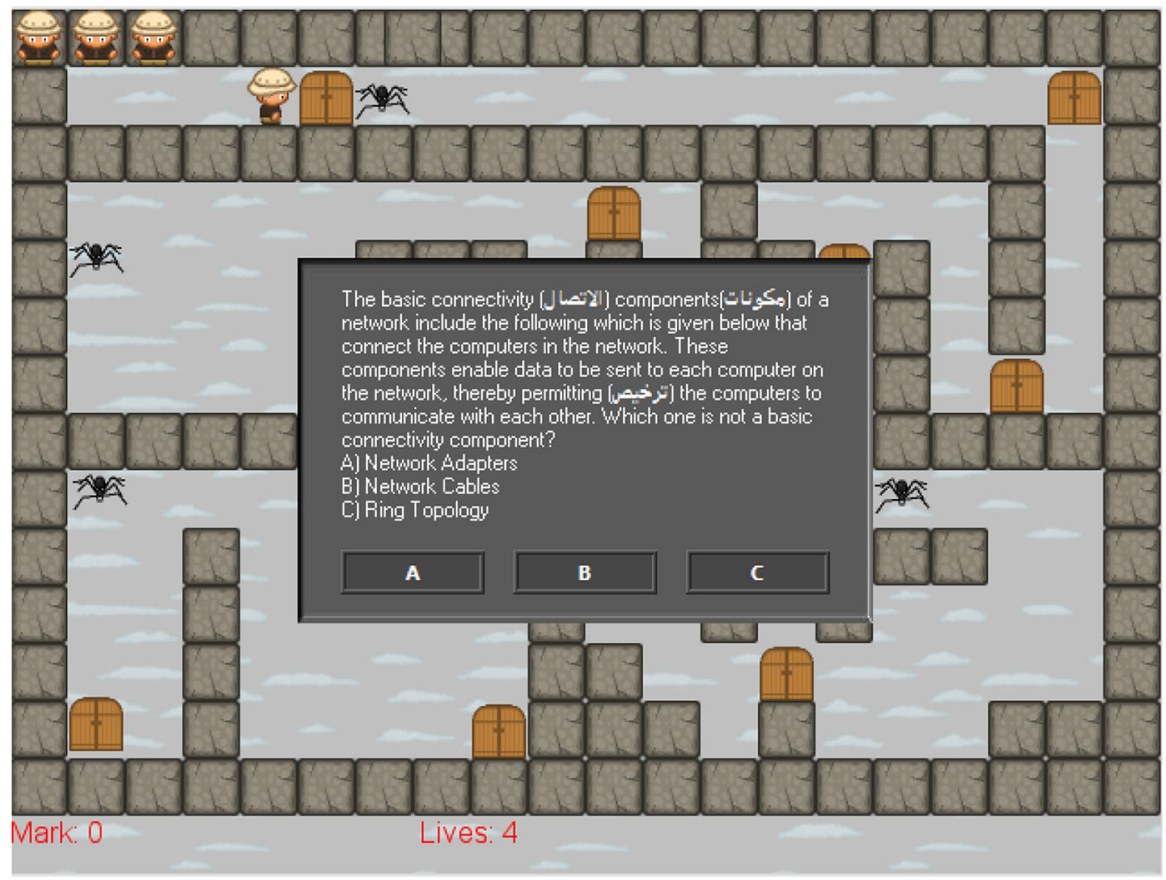

Fig. 1 Example of a room and a question

up-to-date score are continuously displayed, so that student gets instant response regarding his progress. If losing all lives, student gets two options: either terminates the game or restart the game with the current room, which he had managed to reach during the last run of the game. The game was developed using game creation tool Game Maker studio 8.1 (Game Maker 2014) under the platform of Windows 7.

Non-gaming

Quizzes have been created in (Moodle 2014) for non-gaming method as exhibited in Fig. 2. Its learning objectives and content are alike to those of game-based learning. All questions are linked with multimedia learning material, where concepts are explained with the help of image, text, graphics, and animations same like game-based learning. Questions asked in quizzes are similar to those of game-based learning.

The community college is a member of Microsoft Academy (Microsoft IT Academy 2014). Therefore, very nice multimedia teaching material is available for networking course, which includes animated explanation, videos, and images. Figure 3 shows two network concepts that are explained with animation.

Research design

Investigate the performance comparison of game-based learning with native language hint, game-based learning without native language hint, nongame-based 


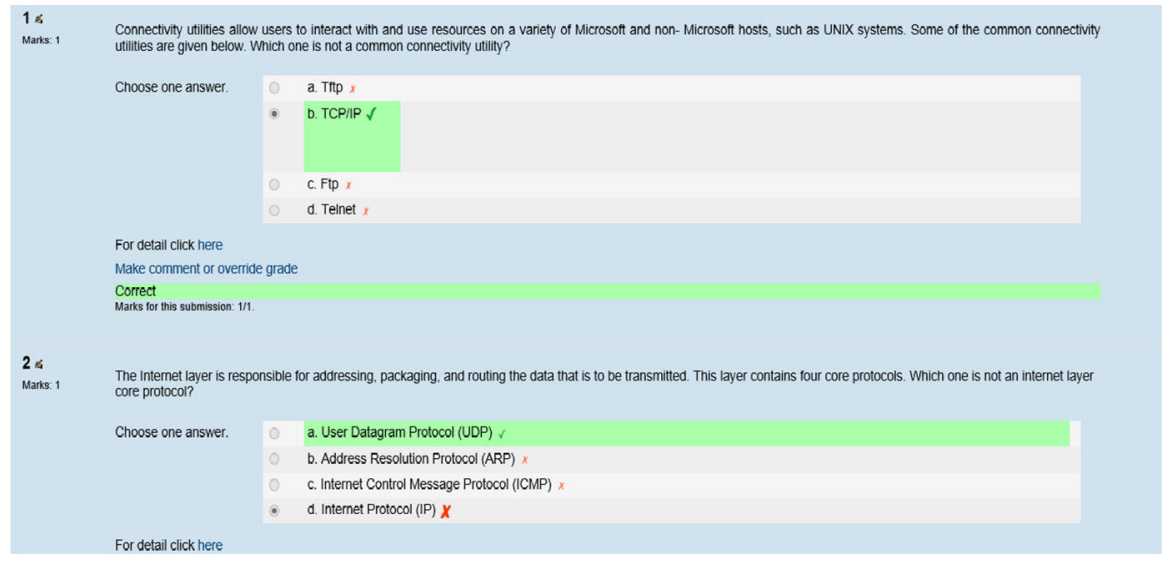

Fig. 2 Example of a quiz in moodle
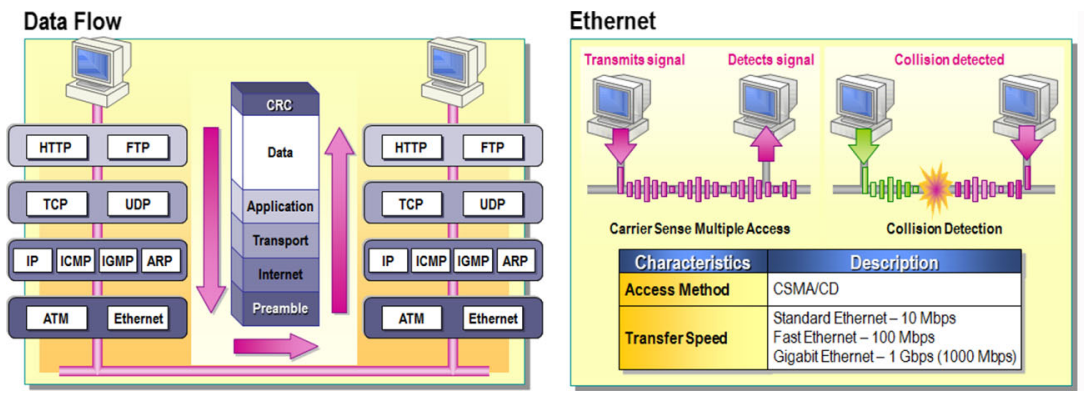

Fig. 3 Example of a Multimedia learning material

with native language hint, and nongame-based learning without native language hint methods. We have conducted a study to analysis these factors and test the possible effects. The research design consists of four steps as shown in (Fig. 4).

The samples were taken from two groups of students. Each group sit for two exams; one without native language hint and other with native language hint. Both groups were located in the same place (Community College of Saudi Arabia). The study tries to analyze the performance between the two groups. The results were analyzed at the end using statistical methods.

\section{Instruments}

For this study, four paper-based questionnaires were constructed: (i) a pretest questionnaire consist of biographical variable, (ii) a pretest subject knowledge test, (iii) a posttest subject knowledge test, and (iv) a posttest feedback questionnaire. The pretest questionnaire produced the following biographical data: age, liking of computer games, frequency of computer gaming, computer gaming experience, type 


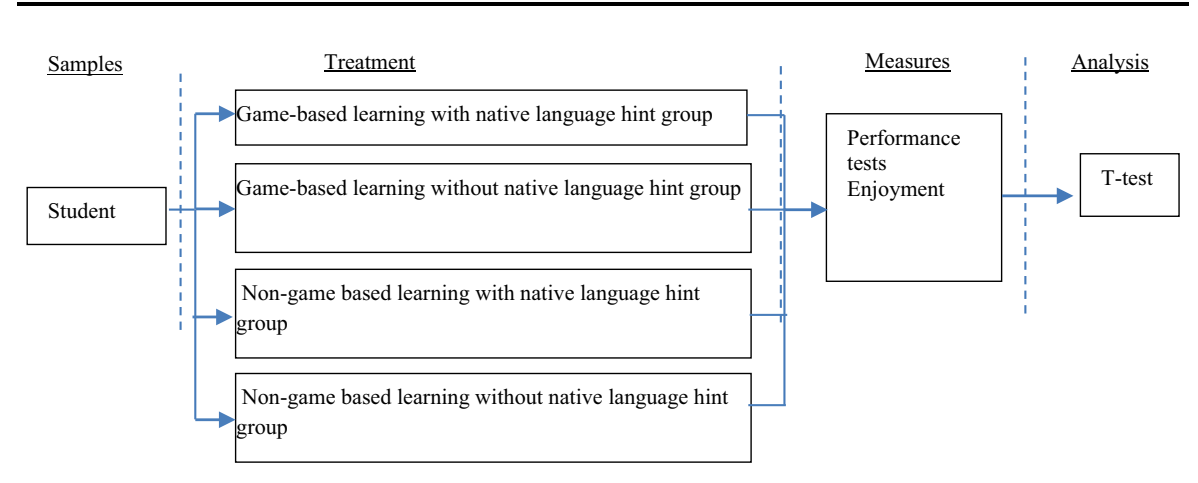

Fig. 4 Graphical representation of the research design of the study

of experience (education game, fighting games, logical games, puzzle games), and favor of game learning. The pretest subject knowledge test questionnaire was aimed at assessing students' subject knowledge prior to the beginning of the interventions. It consisted of a subject knowledge test, which was constructed by the researcher. The test comprised 30 true/false and multiple-choice questions. The first 20 questions derived from the subject matter of the college Network curriculum, and examined as to its content validity by two subject experts of the college. The last 10 questions are constructed to check the subject vocabulary of the students, and these questions are prepared following the guideline of the researcher Paul Nation (2009). The posttest subject knowledge test questionnaire was targeted at measuring students' subject knowledge after the completion of the interventions, and consisted of 30 questions. The second posttest questionnaire was to obtain feedback of the student about different attributes of the game. The questionnaires were divided into two parts enjoyment and usability. Students were asked to rate their experience through a series of closed questions; students were, also, asked to rate on a 5-point scale $(1=$ No, $2=$ Not sure $3=$ A little, $4=$ Very much, $5=$ A lot $)$. We used the following questions: (i) was interesting, (ii) was enjoyable, (iii) was interface user friendly, (iv) was it easy to play, (v) were the instructions straight forward, (vi) graphics used were good, (vi) questions were clear, (vii) did link help you to find the answer, (viii) did game helps you to learn the topic, (ix) do you like to have this game for other subjects, (x) Any suggestions.

Data analysis

There were 44 students involved in the experiment. Before and after playing a game, a performance test was used to measure students' performance. In each of the subject knowledge test (pretest and posttest), the student's number of correct answers was measured as his/her score in the respective test. The scores in each test student can obtain was ranged from 0 to 40 points. The first 20 marks were for subject understanding and last 20 marks for subject vocabulary. An independent samples $t$ test was conducted to compare the performance between two groups. To examine the effect of enjoyment, another independent samples $t$ test was applied. It 
is important to validate the homogeneity of variance and the normality of the sample distribution for the small sample size before applying $t$ test (Nam and Smith-Jackson 2007). Therefore, Kolmogorov-Smirnov was applied to check normality distribution and Levene's test to evaluate homogeneity of variance (Evie 2008). The results of these tests show non-significant outcome $(p>0.05)$, signifying that the samples had homogenous variances and normal distribution of data.

\section{Results}

Comparison of biographical data

The biographical data analysis of students showed that the random assignment of students to the two groups (game-based learning and nongame-based learning) has no statistically significant difference between the two groups. Furthermore, the $t$ test that compared the rest of the biographical variables for the students of game learning group and those of traditional learning group exhibited no statistically significant differences. Table 2 shows the related descriptive statistics.

Comparison of students' subject performance

Using a t-test of the two groups, Game-based Learning $(M=15.95, \mathrm{SD}=2.08)$ and Nongame-based learning $(M=14.1, \mathrm{SD}=2.71)$, a statistically significant main effect was found $(t=2.09, p=0.002)$ in favor of game-based learning group, which indicates that the students who had used the game performed significantly higher in the posttest than those who had not used the game. The analysis of the pretest scores showed that there was no statistically significant difference in the performance in the pretest $(t=2.11, p=0.421)$ between the students of game-

Table 2 Biographical data comparison of the two groups

\begin{tabular}{lccccc}
\hline Variable & \multicolumn{2}{c}{ Game-based } & & \multicolumn{2}{c}{ Nongame based } \\
\cline { 2 - 3 } & $M$ & SD & & $M$ & SD \\
\hline Age & 19.54 & 0.59 & & 19.72 & 0.55 \\
Frequency of computer gaming & 4.13 & 2.03 & & 4.22 & 1.63 \\
Liking of computer game & 3 & 1.19 & & 2.86 & 1.20 \\
Computer gaming experience & 6.9 & 3.49 & & 6.81 & 3.64 \\
\hline
\end{tabular}

Table 3 Performance comparison of the two groups

\begin{tabular}{|c|c|c|c|c|c|c|}
\hline & \multicolumn{2}{|c|}{$\begin{array}{l}\text { Game-based without native language } \\
\text { hint }\end{array}$} & \multicolumn{2}{|c|}{$\begin{array}{l}\text { Nongame-based without native } \\
\text { language hint }\end{array}$} & \multirow[t]{2}{*}{$t$} & \multirow[t]{2}{*}{$p$} \\
\hline & $M$ & SD & $M$ & SD & & \\
\hline Pretest & 15.33 & 2.33 & 16.22 & 2.13 & 2.11 & 0.421 \\
\hline Posttest & 15.95 & 2.08 & 14.1 & 2.71 & 2.09 & 0.002 \\
\hline
\end{tabular}


based $(M=15.33, \mathrm{SD}=2.33)$ and the students of nongame-based $(M=16.22$, $\mathrm{SD}=2.13$ ), which indicates that the two groups had similar background knowledge on computer networking. The pretest and the posttest results of the two groups are shown in Table 3.

\section{Comparison of students' enjoyment and usability}

To examine the research hypotheses regarding the comparison of students' enjoyment among the two groups, the results of the questionnaire are presented in Table 4. The means of the game-based learning method in the two categories (enjoyment and usability) were higher than that of the nongame-based learning method. To further confirm the differences, the variances between the two groups were found to be statistically significant by means of the $t$ test $(t=2.03, p=0.002$; $t=2.02, p=0.01$ in the categories of enjoyment and usability, respectively). This difference indicated that students in game-based learning tasks resulted in increased enjoyment.

\section{Comparison of students' subject vocabulary building}

In order to explore the impact of native language hint, a $t$ test on two groups was conducted. The game-based learning with native language hint $(M=16.55$, $\mathrm{SD}=2.16)$ and nongame-based learning with native language hint $(M=15.25$, $\mathrm{SD}=2.25)$, a statistically significant main effect was found $(t=2.07, p=0.006)$ in favor of game-based learning with native language hint group, which indicates that the students who had used the native language hint build better subject vocabulary than those who had not used the hint. The pretest and the posttest results of the two groups are shown in Table 5.

Table 4 Summary table of $t$ test for questionnaire

\begin{tabular}{|c|c|c|c|c|c|}
\hline & \multicolumn{2}{|c|}{ Game-based } & \multicolumn{2}{|c|}{ Nongame-based } & \multirow[t]{2}{*}{$t$} \\
\hline & $M$ & SD & $M$ & SD & \\
\hline Enjoyment & 3.65 & 0.98 & 2.45 & 1.35 & $2.03^{*}$ \\
\hline Usability & 3.35 & 1.08 & 2.24 & 1.18 & $2.02 *$ \\
\hline
\end{tabular}

$*<0.05$

Table 5 Performance comparison of the two groups

\begin{tabular}{|c|c|c|c|c|c|c|}
\hline & \multicolumn{2}{|c|}{$\begin{array}{l}\text { Game-based with native } \\
\text { language hint }\end{array}$} & \multicolumn{2}{|c|}{$\begin{array}{l}\text { Nongame-based with native } \\
\text { language hint }\end{array}$} & \multirow[t]{2}{*}{$t$} & \multirow[t]{2}{*}{$p$} \\
\hline & $M$ & SD & $M$ & SD & & \\
\hline Pretest & 15.33 & 2.33 & 16.22 & 2.13 & 2.11 & 0.421 \\
\hline Posttest & 16.55 & 2.16 & 15.25 & 2.25 & 2.07 & 0.006 \\
\hline
\end{tabular}


The results of Tables 3 and 5 show that combining game-based learning with native language hint gives better learning opportunity to students when comparing game-based without native language hint, nongame-based with native language hint, and nongame-based without native language hint. Other observation from Tables 3 and 5 is the declining results of non-gaming group. This is due to questions' difficulty level in posttest exam. The posttest exam questions were more difficult than the pretest exam.

Observation of the students' interaction with the applications

According to the informal data gathered from the researcher's observations, the students with average score and less in the pretest seemed more pleased with the native language hint. Students seemed enthusiastic with the game playing. Their level of excitement did not reduce for the entire experiment time frame. They showed high level of engagement by keeping in mind that the status of lives remaining, finish the level fast, and get maximum scores. Interacting with the game they looked very absorbed and interested. The level of competition was very high; they were keen to know other student's score. They were engaged in challenging who will go to the next level first. In addition, it was observed that they even memorized the answers in order to finish the level faster. It seems that the structure of the game was easy to understand and the game was easy to play. Furthermore, students were not seemed to be frustrated from the educational contents.

\section{Discussion and conclusion}

This study evaluates the effectiveness of using game and native language in learning. To proof the concept, we conducted our experiment in teaching computer network concepts on two groups of students: one group uses the game-based learning method and the other group uses the nongame-based learning method and then both groups were tested by providing native language hint and absence of native language hint. The study shows that students using game and native language hint in learning demonstrate better understanding of subject and enjoyment than those who used nongame-based learning without native language hint method. These findings support the results of previous studies by (Ke and Grabowski 2007; Papastergiou 2009a, b), which exhibit that using games in education increases the academic achievement and motivation of students compared to the traditional teaching methods in many disciplines such as Mathematics and Science. This study is different from previous studies in four aspects: (i) this study uses modern interactive e-learning method on both groups, (ii) the participants are Saudi Arabia college students, (iii) effectiveness of native language hint, (iv) the study is applied on complex subject (computer network) whereas the previous studies applied on subject like computer programming (Lawrence 2004). The game developed for this study is relatively simple and contains simple graphics. One of the major findings of this study is that students (college students in our study) learned hard topics and acquired more knowledge when playing educational games with native language 
hint. Hence, we recommend all education institutes to invest time and money to implement game-based teaching with local language hint method on their courses. The other major finding in our study is that students' enjoyment when playing educational game could have remarkable effects on students' learning performance. Although our study shows major improvement in students' performance when using educational games, there are some limitations. First, the generalization of the results must be carefully done since the study was conducted on a specific subject and on college students. Second, the study was conducted and investigated on a short period of time. A long-term study with a follow-up test would have provided more understanding of the effects of educational game on students' performance and motivation. Such research was impossible to conduct due to time limit of each class in community college. The study also open new opportunities for future work. We need to study the right balance between the sophistication and complexity of education games and the effectiveness and performance of learning. Furthermore, future researches are needed to be conducted to study larger samples, different subjects, and investigate long-term learning effects, which may provide more valuable results on game-performance relations. In addition, detailed analyses should be exhibited to realize how gamers' behavior relates to students' learning performance.

\section{References}

Amedeker, M. K. (1998). The place of native language in science teaching and learning in the Junior Secondary Schools in Ghana. Journal of Ghana Science Association, 1(1), 7-11.

Cagiltay, N. E. (2007). Teaching software engineering by means of computer-game development: Challenges and opportunities. British Journal of Educational Technology, 38(3), 405-415.

Ebner, M., \& Holzinger, A. (2007). Successful implementation of user-centered game based learning in higher education: an example from civil engineering. Computers and Education, 49(3), 873-890.

Evie, M. (2008). Which is the correct statistical test to use? British Journal of Oral and Maxillofacial Surgery, 46, 38-41.

Game Maker (2014). https://www.yoyogames.com/studio. Accessed 20 May 2014.

Gentile, D. A., Anderson, C. A. (2003). Violent video games: The newest media violence hazard. Video Games Suggestions, 131-153.

Giumetti, G. W., \& Markey, P. M. (2007). Violent video games and anger as predictors of aggression. Journal of Research and Personality, 41(6), 1234-1243.

Gonzalez-Gonzalez, C., \& Blanco-Izquierdo, F. (2012). Designing social videogames for educational uses. Computers and Education, 58, 250-262.

Gulf News gulfnews.com. (2014). http://gulfnews.com/business/technology/arabonline-gaming-marketgrowing-at-exponentialrate-1.720552. Accessed 4 April 2014.

Microsoft IT Academy (2014). http://www.microsoft.com/education/itacademy/Pages/index.aspx. Accessed 4 May 2014.

Harris, J. (2001). The effects of computer games on young children: A review of the research. London: Research, Development and Statistics Directorate.

Hsu, S. H., Wen, M. H., \& Wu, M. C. (2009). Exploring user experiences as predictors of MMORPG addiction. Computers and Education, 53(3), 990-999.

Huang, W. H., Huang, W. Y., \& Tschopp, J. (2010). Sustaining iterative game playing processes in DGBL: the relationship between motivational processing and outcome processing. Computers and Education, 55(2), 789-797. 
Hwang, G. J., \& Wu, P. H. (2012). Advancements and trends in digital game-based learning research: a review of publications in selected journals from 2001 to 2010. British Journal of Educational Technology, 43(1), E6-E10.

Inal, Y., \& Cagiltay, K. (2007). Flow experiences of children in an interactive social game environment. British Journal of Educational Technology, 38(3), 455-464.

Ke, F., \& Grabowski, B. (2007). Game playing for maths learning: Cooperative or not? British Journal of Educational Technology, 38, 249-259.

Klopfer, E., Osterweil, S., Salen, K. (2009). Moving learning games forward, obstacles opportunities and openness. Cambridge MA: MIT/The Education Arcade (Online), http://education.mit.edu/papers/ MovingLearningGamesForward_EdArcade.pdf.

Lawrence, R. (2004). Teaching data structures using competitive games. IEEE Transactions on Education, 47(4), 459-466.

Mayer, R. E. (2001). Multi-media learning. Cambridge: Cambridge University Press.

McFarlane, A., Sparrowhawk, A., Heald, Y. (2002). Report on the educational use of games. http://www. teem.org.uk/publications/teem_gamesined_full.pdf .

Mikalef, K., Giannakos, M. N., Chorianopoulos, K., Jaccheri, L. (2012). "Do not touch the paintings!" The benefits of interactivity on learning and future visits in a museum. In Entertainment computing: ICEC 2012, Vol. 7522/2012 (pp. 553-561).

Moodle (2014). http://moodle.com. Accessed 16 May 2014.

Nam, C. S., \& Smith-Jackson, T. L. (2007). Web-based learning environment: a theory-based design process for development and evaluation. Journal of Information Technology in Education, 6, 23-43.

Natvig, L., \& Line, S. (2004). Age of computers: Game-based teaching of computer fundamentals. ACM SIGCSE Bulletin, 36(3), 107-111.

Nordkvelle, Y. T., Fritze, Y., Haugsbakk, G. (2009). The visual in teaching from Bologna to YouTubiversity. Medien-Wissen-Bildung: University of Innsbruck. http://media.brainity.com/ uibk2/amab2010/images/down/MWB09_Proceedings.

Oggins, J., \& Sammis, J. (2012). Notions of video game addiction and their relation to self-reported addiction among players of world of warcraft. International Journal of Mental Health and Addiction, 10(2), 210-230.

Papastergiou, M. (2009a). Digital game-based learning in high school computer science education: impact on educational effectiveness and student motivation. Computers and Education, 52(1), 1-12.

Papastergiou, M. (2009b). Digital game-based learning in high-school computer science education: impact on educational effectiveness and student motivation. Computers and Education, 52(1), 1-12.

Papastergiou, M., \& Solomonidou, C. (2005). Gender and information and communications technology: Greek high school students' favorite internet activities. Computers and Education, 44(4), 377-393.

Paul Nation, I.S.P. (2009). New roles for L2 vocabulary? In L. Wei \& V. Cook (Eds.), Contemporary applied linguistics Vol. 1: Language teaching and learning continuum (pp. 99-116), Chap. 5.

Petty, G. (1997). How to be better at creativity. London: Kogan Page Limited.

Pivec, M. (2007). Play and learn: Potential of game-based learning. British Journal of Educational Technology, 38(3), 387-393.

Prensky, M. (2001). Digital Game-Based Learning. NewYork: McGraw- Hill.

Prensky, M. (2007). Emerging technologies for learning, Vol. 2 (2007). British Education Communications and Technology Agency (BECTA).<http://www.becta.org.uk>. Accessed 10 November 2007.

Prensky, M. (2008). Students as designers and creators of educational computer games: who else? British Journal of Educational Technology, 39(6), 1004-1019.

Project Tomorrow. (2008). Speak up 2007 for students, teachers, parents and school leaders selected national findings. http://www.tomorrow.org/docs/National. Accessed 8 April 2008.

Roussou, M. (2004). Learning by doing and learning through play: An exploration of interactivity in virtual environments for children. Computer in Entertainment, 2(1), 10.

Saleh, Alshair. (2014). "The language of science education: Between two trends" (Scidev.net, 8 August 2014).

Shin, N., Sutherland, L. M., Norris, C. A., \& Soloway, E. (2012). Effects of game technology on elementary student learning in mathematics. British Journal of Educational Technology, 43, 540-560.

Starcevic, V., Berle, D., Porter, G., \& Fenech, P. (2011). Problem video game use and dimensions of psychopathology. International Journal of Mental Health and Addiction, 9(3), 248-256. 
Tüzün, H., Yılmaz-Soylu, M., Karakus, T., Inal, Y., \& Kızılkaya, G. (2009). The effects of computer games on primary school students' achievement and motivation in geography learning. Computers and Education, 52(1), 68-77.

Venkatesh, V. (2000). Determinants of perceived ease of use: integrating control, intrinsic motivation, and emotion into the technology acceptance model. Information Systems Research, 11, 342-365.

Virvou, M., \& Katsionis, G. (2008). On the usability and likeability of virtual reality games for education: The case of VR-ENGAGE. Computers and Education, 50, 154-178.

Whitton, N. (2007). An investigation into the potential of collaborative computer game-based learning in higher education. Unpublished doctoral dissertation, Napier University.

Williamson, B. (2009). Computer games, schools, and young people: A report for educators on using games for learning. http://archive.futurelab.org.uk/resources/ documents/project_reports/becta/ Games_and_Learning_educators_report.pdf.

Zhi, H., \& Zhang, Z. H. (2008). Integration of game elements with role play in collaborative learning: A case study of quasi-GBL in Chinese higher education. Technologies for E-Learning and Digital Entertainment. Lecture Notes in Computer Science, 5093(2008), 427-435.

Bassam Zafar is an assistant professor in Information System Department, King Abdulaziz University Jeddah. His research interests include Cloud computing, Service Oriented Architecture, Artificial Intelligent and Game-based learning.

Ahmed Mueen is an assistant professor in King Abdulaziz University Jeddah. His research interests include Game-based learning, mobile learning, information retrieval, and image processing.

Mohammad Hamza Awedh is an assistant professor in Department of Electrical and Computer Engineering, King Abdulaziz University Jeddah. His research interests include Game-based learning, Data mining, and Formal verification of hardware and software systems.

Mohammed A Balubaid is an assistant professor in the Industrial engineering department at King Abdulaziz University, where he has been a faculty member since 2009. He received the BEng. degree in manufacturing system engineering and MSc. in Engineering Management from the University of Warwick UK, in 2001 and 2002 respectively, and the Ph.D. degrees in engineering management from the University of Manchester UK, in 2007. His current research interests include industrial engineering application, technical entrepreneurship and the use of technology in education. 